\title{
Are family allowances and fertility-related pensions Siamese twins?
}

\author{
Robert Fenge and Volker Meier* \\ Ifo Institute for Economic Research, \\ University of Munich, and CESifo \\ Poschingerstr. 5, D-81679 Munich, Germany \\ E-mail: fenge@ifo.de; meier@ifo.de
}

December 11, 2003

\begin{abstract}
This paper discusses alternative ways to deal with the positive externalities of having children in a pay-as-you-go pension system. Family allowances are compared to introducing a fertility-related component into the pension formula. In an endogenous labor supply setting, both instruments are shown to be equivalent if general pensions are of the Bismarckian contribution-related type. In contrast, if general pensions are of the Beveridgean flat-rate type, making pensions contingent on the number of children is generally preferable to family allowances because the latter creates a larger tax load on labor supply.
\end{abstract}

Keywords: Pay-as-you-go pension; Child benefits; Fertility; Fxternalities JEL classification: H23; H55; J13; J18

\footnotetext{
${ }^{*}$ Corresponding author
} 


\section{Introduction}

Having children generally creates a positive fiscal externality if a public payas-you-go (PAYG) pension system is in place. In such a scheme the active generation pays the current pensions of the old generation. The return on social security contributions depends on average fertility in the economy, and is therefore raised through a higher number of children. Pension formulas usually ignore this link and either, in a Bismarckian system, distribute benefits according to previous contributions, or, in a Beveridgean scheme, set a uniform pension for everybody. From an individual's perspective, the pension claim does not increase with a higher number of children. The pension of parents will even fall short of the old-age income of couples without children if public pensions are earnings-related and, in addition, parents have to reduce their lifetime labor supply in order to raise children. It can therefore be argued that the extension of PAYG pension systems after the Second World War has contributed to the secular decline in fertility levels. This hypothesis is confirmed by Cigno and Rosati (1996), and Cigno et al. (2003), who investigate the cases of Germany, Italy, the UK, and the United States. The prediction of a declining fertility as a response to an expanding public pension system is generally also obtained if children respond by decreasing their income support towards their parents (Wigger, 1999).

The literature focuses on two main policy instruments that may be used to overcome the distortion of fertility incentives, namely family allowances and fertility-related pensions. While in each case some benefit per child is paid to parents, the age of the recipients differs. In our framework, fertilityrelated pensions are paid at a given tax rate for social security contributions. Therefore, if pensions are partially made contingent on fertility, general Bismarckian or Beveridgean pensions will typically decline. Our main question is whether the two instruments constitute perfect substitutes and can therefore be called "Siamese twins" (van Groezen et al., 2003). Should this be the case, correcting the distortion can be achieved by a continuum of solutions, including the exclusive use of any of the two instruments. Otherwise, it is clearly important to derive which instrument mix maximizes lifetime utility. Moreover, we discuss whether the optimum share of fertility-related pensions in the PAYG scheme does ever reach unity. These issues are analyzed in an endogenous labor supply setting where factor prices are fixed by considering a small open economy framework and both pensions and family allowances have to be financed by a payroll tax. 
Our comparative static analysis stresses the impact of taxes on household labor supply. Since we assume homogenous households, taxes used for financing fertility-related benefits in the same generation are not associated with any direct income effect. Thus, both measures discussed here simply reduce the price of a child, where only the substitution effect is at work, inducing an increase in fertility. Levying taxes on labor will drive down labor supply since income losses for unchanged behavior are fully compensated by rising benefits contingent on the number of children. However, it cannot be excluded that an indirect income effect pushes labor supply in the opposite direction. Should a higher number of children be associated with a reduction of the individual's lifetime consumption, there is a tendency to increase labor supply. Further, it is possible to construct examples where an increasing family allowance yields lower fertility due to a fall in labor supply.

We demonstrate that fertility-related PAYG pensions and family allowances can be considered as Siamese twins under the Bismarckian pension system. On the one hand, financing family allowances requires the taxing of current wage income. On the other hand, raising the share of fertility-related pensions means reducing the share of general pension claims. But the general pension in a Bismarckian system can be interpreted as wage income to be paid after retirement. Hence, both instruments tax labor supply in that case. It turns out that the same impact on fertility is achieved with the same distortion of labor supply.

This result does not hold if general pensions are unrelated to contributions, as in the Beveridgean scheme. The contribution towards a flat-rate PAYG scheme constitutes a tax irrespective of the shares of general and fertility-related pensions. Introducing family allowances still increases the tax on labor supply and thus enlarges the distortion in labor supply. Provided that the share of fertility-related pensions is below its maximum, using exclusively fertility-related pensions will therefore be associated with higher welfare than having some element of family allowances.

If the government only relies on fertility-related pensions, its utilitymaximizing share in a steady state may both be smaller or equal to unity. If the full pension is contingent on the number of children, the relevant externality arises from the fact that children do not take into account the impact of their demand for leisure on the wellbeing of pensioners. Should a marginal decrease of the child factor in the pension scheme then lead to a rise in labor supply, the optimum share of fertility-related pensions will be smaller than unity. In the opposite case, lifetime utility can further be increased by 
introducing family allowances if this yields a rising labor supply.

Our results partially contradict previous findings in the literature. Van Groezen, Leers and Meijdam (2000, 2003) analyze the option of introducing child benefits so as to generate a first-best allocation. The optimum family allowance is equal to the present value of the child's contribution towards the pension scheme. As also shown by Sinn (2001), this amount represents the net social gain of an additional individual given that her pension will be financed by her children. In the exogenous labor supply framework of van Groezen et al. (2003), the first-best allocation can also be achieved by making pensions contingent on the number of children. The two instruments family allowances and fertility-related pensions can therefore be viewed as Siamese twins. Fenge and Meier (2003) consider a situation in which labor supply is tied to the number of children, where parents reduce household labor supply with a higher number of children. Unlike the message for an exogenous labor supply framework discussed by Kolmar $(1997,2001)$, it is then no longer true that the optimum share of fertility-related pensions is unity. The share of general pensions remains positive since children do not take into account the fall in their parent generation's pensions when they increase the number of children and thus reduce labor supply. However, Fenge and Meier (2003) also show that the Siamese twins property still holds if labor supply is driven by fertility. The optimum allocation can be achieved by a continuum of combinations of fertility-related pensions and family allowances, including the polar cases where only one instrument is used.

Another consideration put forward by Cigno and Luporini (2003) calls for using child benefits in a fashion where parents directly collect parts of their children's social security contributions. Such a scheme encourages unobservable investment in human capital. Since the return on investment is uncertain, it turns out to be optimal to also give some benefit, regardless of the child's success, as a family allowance or a fertility-related pension. In contrast, the problem of inducing the efficient education level can be solved through a public education system or subsidies for private education. A debt policy may then be used where each individual pays for her share of the return to education. However, for a closed economy framework, Peters (1995) stresses that a quality-quantity trade-off works such that eduation will always be subsidized, while fertility may even be taxed. A similar argument in favor of positive growth impacts of reducing fertility by extending an unfunded pension scheme has been developed by Zhang (1995).

It should be noted that the relevant policy comparison requires that the 
size of the PAYG pension scheme is kept constant. Alternatively, it may be plausible to have a given social security tax towards the general pension scheme, and top this up by an additional PAYG scheme that finances fertility-related pensions. As argued by Fenge and Meier (2003), having family allowances as an alternative then amounts to comparing PAYG schemes of different size. Such a comparison will usually be governed by the Aaron (1966) condition, stating that extending the PAYG scheme increases steadystate utility levels if the rate of population growth exceeds the interest rate, and vice versa.

The remainder of the paper is organized as follows. Section 2 introduces the model. The comparative static analysis in section 3 deals with the impacts of changing either the child factor in the pension scheme or the level of family allowances on fertility and labor supply. Section 4 investigates the main question whether child benefits should be paid within the pension system or, alternatively, via family allowances. Section 5 discusses the choice of the child factor in the pension scheme. Section 6 concludes and indicates directions for future research.

\section{The basic model}

We use a three-period overlapping generations model. For simplicity, we consider a one-sex population consisting of females. All households within a generation are identical. Thus, a redistribution of income within a generation will not take place in equilibrium.

A generation lives for three periods. In the first period, an individual lives with her parent, where the direct cost of a child is $q$. Education is ignored in the following. Notice that the problem of correcting the fertility incentives would remain if the provision of schooling is set at the efficient level.

In the second period, the household chooses her labor supply $1-l_{t}$, where total available time is normalized to unity and $l_{t}$ denotes leisure. The household earns a wage rate $w_{t}$ and decides how much to save, $s_{t}$, and to consume, $c_{t}$. Moreover, the household chooses the number of children, $n_{t+1}$, that she will have in this period. These children enter the labor force in period $t+1$. In order to simplify the analysis, $n_{t+1}$ can be chosen from the set of nonnegative real numbers. Furthermore, in the second period the household receives a family allowance $a_{t}$ for each child she brings up. The household has to pay contributions to the pay-as-you-go pension system and pays taxes 
in order to finance family allowances. The contribution rate is $\tau_{t}$, and the tax rate is $\theta_{t}$.

$$
c_{t}+s_{t}+q n_{t+1}=\left(1-\tau_{t}-\theta_{t}\right)\left(1-l_{t}\right) w_{t}+a_{t} n_{t+1} .
$$

Labor supply is unrelated to the number of children, which may be the consequence of a universal coverage by public child care facilities. In fact, there has been some doubt that the traditional negative relationship between fertility and female labor supply is still valid. While observations from several OECD countries during the last two decades even suggest a positive association (Ahn and Mira, 2002), the perceived change of signs can also be interpreted as a statistical artefact being caused by exogenous factors that simultaneously influence both fertility and labor supply (Kögel, 2002).

In the third period the household retires and consumes $z_{t+1}$. Old age consumption equals the sum of private savings multiplied by the interest factor $R_{t+1}$, and the pension $p_{t+1}$.

$$
z_{t+1}=R_{t+1} s_{t}+p_{t+1}
$$

The utility function $U\left(c_{t}, z_{t+1}, n_{t+1}, l_{t}\right)$ is continuous, strictly concave, and strictly increasing in consumption and leisure. The partial derivative of $U$ with respect to its $i^{\text {th }}$ argument is denoted by $U_{i}$. Utility has a bliss point $\tilde{n}>0$ in the number of children, that is, we have $U_{3}>0$ for $n<\tilde{n}$ and $U_{3}<0$ for $n>\tilde{n}$. In order to keep the notation simple, we assume that the utility function exhibits additive seperability. Hence, the cross derivatives of the utility function are zero: $U_{x y}=0$ for $x, y \in\{1,2,3,4\}, x \neq y$.

The government runs a pension system and a budget for family allowances. In period $t$ the size of the working population is $N_{t}$. The growth factor of the young generation in period $t+1$ is defined as $N_{t+1} / N_{t}=\bar{n}_{t+1}$. The contribution revenues of the pay-as-you-go financed pension scheme in period $t+1$ are used to finance the pension $p_{t+1}$ of the $N_{t}$ retirees of generation $t$. The pension of a household depends with a share $\alpha$ of the contributions on the number of children of the household and with a share $1-\alpha$ on the aggregate growth factor of the population, where $0 \leq \alpha \leq 1$. In the following we call the policy variable $\alpha$ the child factor. The pension of an individual is given by

$$
p_{t+1}=\tau_{t+1} w_{t+1}\left(1-\bar{l}_{t+1}\right)\left[(1-\alpha) \bar{n}_{t+1} \frac{1-l_{t}}{1-\bar{l}_{t}}+\alpha n_{t+1}\right]
$$


where $1-\bar{l}_{t}$ denotes the average labor supply of the individuals working in period $t$. Of course, as we assume that all individuals within a generation are identical, we have $\bar{l}_{t}=l_{t}$ in equilibrium. Notice that $\tau_{t+1} w_{t+1}\left(1-\bar{l}_{t+1}\right)$ is the average contribution of an individual working in period $t+1$. The parent collects the share $\alpha$ of the contributions of her $n_{t+1}$ children. The remainder is spent in the general scheme in which $\bar{n}_{t+1}$ contributors finance one pensioner. In a Bismarckian system, the pension fund is distributed according to contributions, being expressed by the factor $\frac{1-l_{t}}{1-\bar{l}_{t}}$. Under a flat pension system of the Beveridgean type, the corresponding factor is always equal to one.

The tax revenues in period $t$ are used to finance the family allowances in the same period. The benefit for a child of an individual is given by

$$
a_{t}=\frac{\theta_{t} w_{t}\left(1-\bar{l}_{t}\right)}{\bar{n}_{t+1}} .
$$

Inserting (1)-(4) into the utility function yields the maximization problem

$$
\begin{gathered}
\underset{s_{t}, n_{t+1}, l_{t}}{\operatorname{Max}} U\left\{\left(1-\tau_{t}-\theta_{t}\right)\left[1-l_{t}\right] w_{t}+\left[\frac{\theta_{t} w_{t}\left(1-\bar{l}_{t}\right)}{\bar{n}_{t+1}}-q\right] n_{t+1}-s_{t},\right. \\
R_{t+1} s_{t}+\tau_{t+1} w_{t+1}\left(1-\bar{l}_{t+1}\right) \\
\left.\cdot\left[(1-\alpha) \bar{n}_{t+1} \frac{1-l_{t}}{1-\bar{l}_{t}}+\alpha n_{t+1}\right], n_{t+1}, l_{t}\right\} .
\end{gathered}
$$

We assume that an interior solution to this problem exists. The economy is large in the sense that the individual ignores the impact of her fertility and labor supply decisions on average fertility and labor supply per capita. The first-order conditions determine the household's optimal decisions:

$$
\begin{gathered}
U_{s}=-U_{1}+R_{t+1} U_{2}=0 \\
U_{n}=U_{1}\left(\frac{\theta_{t} w_{t}\left(1-\bar{l}_{t}\right)}{\bar{n}_{t+1}}-q\right)+U_{2} \tau_{t+1} w_{t+1}\left(1-\bar{l}_{t+1}\right) \alpha+U_{3}=0 \\
U_{l}=-U_{1}\left(1-\tau_{t}-\theta_{t}\right) w_{t}+U_{2} \frac{\partial p_{t+1}}{\partial l_{t}}+U_{4}=0
\end{gathered}
$$


with $\frac{\partial p_{t+1}}{\partial l_{t}}=-\tau_{t+1} w_{t+1}(1-\alpha) \bar{n}_{t+1} \frac{1-\bar{l}_{t+1}}{1-\bar{l}_{t}}<0$ in a Bismarckian system whereas $\frac{\partial p_{t+1}}{\partial l_{t}}=0$ if a Beveridgean scheme is in place. The derivatives with respect to the optimization variables are represented by $U_{s}=\frac{\partial U}{\partial s_{t}}$, $U_{n}=\frac{\partial U}{\partial n_{t+1}}$, and $U_{l}=\frac{\partial U}{\partial l_{t}}$. As it is demonstrated in Appendix A, the objective function is strictly concave in the decision variables both under the Bismarckian and under the Beveridgean scheme, ensuring uniqueness of the maximum.

According to equation (7), the number of children is chosen such that the marginal utility of an additional child offsets the marginal disutility from consumption during the active period due to the net cost of a child, $q-a_{t}$, and the marginal benefit arising through higher fertility-related pensions. If monetary incentives set by family allowances and fertility-related pensions are strong, the number of children can exceed the individual's bliss point. The optimality condition (8) can be interpreted as follows. The marginal disutility of leisure, resulting from a lower net wage income and - under a Bismarckian regime - a reduced contribution-related pension, is equal to the direct marginal benefit of leisure.

\section{Comparative statics}

Proposition 1 describes how fertility and labor supply of a household react to a rising child factor in the pension system. While the impact on fertility is unsurprising, the possible fall in labor supply can be traced back to a substitution effect that may even be reinforced by an indirect income effect.

Proposition 1 Fertility increases with a higher child factor in the pension system. Labor supply decreases if the price of a child, $q-a_{t}-\frac{\tau_{t+1} w_{t+1}}{R_{t+1}}(1-$ $\left.\bar{l}_{t+1}\right) \alpha$, is negative. Under a Beveridgean regime, labor supply increases if the price of a child is positive.

Proof. See Appendix B.

The intuition for the results is straightforward. A higher child factor changes the structure of the pension income in favor of the child-related component. This increases the marginal benefit of having children, yielding 
a higher fertility level. If the price of a child is negative, having more children leads to a higher lifetime income. This occurs if the additional family allowances and fertility-related pensions exceed the cost of a child. Consequently, demand for the normal good leisure goes up and labor supply is reduced. Conversely, should the price of a child be positive, there is a tendency to increase labor supply. In addition, the price of leisure falls with a smaller share of earnings-related pensions if a Bismarckian pension scheme prevails. This increases the demand for leisure. The associated loss in income will partially be compensated for by having more children if the price of a child is negative, and vice versa. It turns out that the impact on fertility is unambiguous even if a Bismarckian pension scheme is in place.

Proposition 2 considers the impacts of an increase in the tax rate $\theta_{t}$. This corresponds to a higher level of family allowances per child where the family allowance budget of the government is kept balanced for unchanged behavior. Again, a combination of substitution and indirect income effects may cause a falling labor supply.

Proposition 2 Fertility increases with a higher tax for family allowances under a Bismarckian pension scheme. If a Beveridgean scheme is in place, fertility increases if lifetime consumption does not fall short of the general pension, that is, if $R_{t+1} c_{t}+z_{t+1}-\tau_{t+1} w_{t+1} \bar{n}_{t+1}\left(1-\bar{l}_{t+1}\right)(1-\alpha) \geq 0$. Labor supply decreases under both systems if the price of a child is not positive. Under a Beveridgean regime, labor supply also falls if the price of a child is positive and lifetime consumption does not exceed the general pension.

Proof. See Appendix C.

A higher tax for financing family allowances amounts to a pure redistribution in a homogenous population. Thus, there is no immediate income effect on fertility and labor supply. However, both the price of a child and the price of leisure go down. The substitution effects of a higher tax along with a higher family allowance imply a rising demand for children and leisure. The latter decreases wage income while the former raises income if the price of a child is negative, and reduces income if the price of a child is positive. Wage income losses arising from a reduction of labor supply are partially compensated by having more children should the price of a child be negative, while the demand for children decreases in the opposite case. If the price of a child is negative, a higher fertility due to the substitution effect will be accompanied by an increased demand for leisure. In contrast, income 
losses that arise if the price of a child is positive tend to raise labor supply. The condition that lifetime consumption does not fall short of the general pension will generally be satisfied. Hence, the message of Proposition 2 is that fertility will almost always increase, even if the indirect income effect works against the substitution effect. While labor supply tends to fall, it cannot be excluded that the indirect income effect offsets the substitution effect should the price of a child be positive. As shown in Appendix D, it is indeed possible that fertility declines. Such a counterintuitive reaction will always be accompanied by a fall in labor supply.

\section{Child factor versus family allowances}

An interesting issue to explore is whether or not introducing a child factor into the pension formula is preferable to using family allowances when considering lifetime utility. One main advantage of having a child factor rather than family allowances is that the economy can get rid of the distortion of the labor supply decision that arises through the payroll tax to finance family allowances. However, in a Bismarckian pension scheme, introducing a child factor at a given contribution rate also amounts to taxing labor supply since individuals lose earnings-related pensions. Proposition 3 shows that both instruments are equivalent under these circumstances.

Proposition 3 Under a Bismarckian pension scheme, family allowances and fertility-related pensions constitute perfect substitutes.

Proof. Notice that the two budget equations of the household under a Bismarckian pension scheme can be combined to arrive at

$$
\begin{aligned}
& \left(1-\tau_{t}-\theta_{t}\right) w_{t}+\frac{\tau_{t+1} w_{t+1}\left(1-\bar{l}_{t+1}\right)}{R_{t+1}\left(1-\bar{l}_{t}\right)}(1-\alpha) \bar{n}_{t+1} \\
= & c_{t}+\frac{1}{R_{t+1}} z_{t+1}+\left[q-\frac{\theta_{t} w_{t}\left(1-\bar{l}_{t}\right)}{\bar{n}_{t+1}}-\alpha \frac{\tau_{t+1} w_{t+1}\left(1-\bar{l}_{t+1}\right)}{R_{t+1}}\right] n_{t+1} \\
& +\left[\left(1-\tau_{t}-\theta_{t}\right) w_{t}+\frac{\tau_{t+1} w_{t+1}\left(1-\bar{l}_{t+1}\right)}{R_{t+1}\left(1-\bar{l}_{t}\right)}(1-\alpha) \bar{n}_{t+1}\right] l_{t} .
\end{aligned}
$$

The left-hand side of $(9)$ is the household's income while the right-hand side shows the expenditure side. Let $\left(\alpha_{0}^{*}, \theta_{0}^{*}\right)$ denote an optimal vector of 
instruments with $\alpha_{0}^{*}>0$ or $\theta_{0}^{*}>0$, yielding an allocation $\left(c_{t}^{*}, z_{t+1}^{*}, n_{t+1}^{*}, l_{t}^{*}\right)$ that maximizes lifetime utility. If $\alpha$ and $\theta$ are varied such that

$$
d \theta=-d \alpha \frac{\tau_{t+1} w_{t+1}}{w_{t} R_{t+1}} n_{t+1}^{*} \frac{1-l_{t+1}^{*}}{1-l_{t}^{*}}
$$

all prices and the household's income remain constant. Thus, the same decisions will be taken, implying an identical allocation.

Thus, under a Bismarckian system an optimum allocation can generally be achieved both with a combination of the child factor and the family allowance and an exclusive use of only one instrument. Increasing any of the two policy parameters reduces both income and the price of leisure. The price of a child falls. It turns out that the two instruments affect income and the two variable prices in a perfectly symmetrical fashion. As it will be demonstrated in the next section, utilizing only one instrument may not be sufficient in order to maximize lifetime utility. Such a situation may occur if welfare gains can be achieved by introducing the second instrument when the other policy parameter is already set at its maximum level.

The equivalence result does not carry over to a Beveridgean scheme. The combined budget equation then reads

$$
\begin{aligned}
& \left(1-\tau_{t}-\theta_{t}\right) w_{t}+\frac{\tau_{t+1} w_{t+1}\left(1-\bar{l}_{t+1}\right)}{R_{t+1}}(1-\alpha) \bar{n}_{t+1} \\
= & c_{t}+\frac{1}{R_{t+1}} z_{t+1}+\left[q-\frac{\theta_{t} w_{t}\left(1-\bar{l}_{t}\right)}{\bar{n}_{t+1}}-\alpha \frac{\tau_{t+1} w_{t+1}\left(1-\bar{l}_{t+1}\right)}{R_{t+1}}\right] n_{t+1} \\
& +\left(1-\tau_{t}-\theta_{t}\right) w_{t} l_{t} .
\end{aligned}
$$

In contrast to the Bismarckian system, the income expression is larger, and only the family allowance tax affects the price of leisure. Proposition 4 shows that family allowances bear a substantial disadvantage compared to making pensions contingent on fertility if the general PAYG pension is flat.

Proposition 4 With a Beveridgean pension scheme, the optimum allocation $\left(c_{t}^{*}, z_{t+1}^{*}, n_{t+1}^{*}, l_{t}^{*}\right)$ requires that the family allowance tax is not positive if the child factor remains below its maximum level, that is, $\alpha<1$.

Proof. See Appendix E.

The proposition can be explained as follows. All impacts of changing the policy parameters work through influencing per capita demand for children 
and leisure. As demonstrated above, the use of both instruments is virtually always associated with higher fertility. This increases lifetime income by raising the general pension. Noting that the family allowance has to be reduced at a given tax rate, it also yields a higher price of children. A falling labor supply decreases income because social security contributions per capita being spent on pensions go down. The price of a child is increased due to the necessary reduction of the family allowance and the smaller fertility-related transfer to pensioners at a given social security tax rate. Hence, a fall in labor supply per capita has an unambiguously negative effect on utility.

Since the family allowance tax reduces the price of leisure, it entails a negative impact on labor supply being absent with fertility-related pensions. The main part of the proof considers a situation in which the child factor is increased at the expense of a lower family allowance tax so as to keep fertility constant. This variation increases average labor supply in the economy, being associated with a higher welfare level. This experiment can be repeated as long as the family allowance tax is positive. It cannot be excluded that lifetime utility can be further increased by introducing a family allowance tax if the share of fertility-related pensions is already at its maximum level. We will show in the next section that such a situation requires a positive marginal impact of the family allowance tax on labor supply.

Our results suggests that using fertility-related pensions rather than relying on family allowances yields a higher welfare level if there is some flat rate element in the pension formula. The only justification for family allowances would then lie in overcoming credit constraints for young families. However, the analysis indicates that this argument is flawed since the government can simply offer to borrow against future fertility-related pension claims.

\section{Optimum child factor}

The preceding section has shown that correcting the distortion of the fertility decision can generally be achieved by an exclusive use of fertility-related pensions. An interesting question is now which level of the child factor would maximize utility in the steady state in the absence of family allowances. In our representative agents framework one is tempted to assume that increasing the child factor to unity eliminates all externalities associated with having children. It turns out, however, that the labor supply reaction to an increasing child factor plays a crucial role in this respect. 
In the absence of a family allowance system, the indirect utility function under a Bismarckian scheme is given by

$$
\begin{aligned}
V(\alpha)= & U\left\{\left(1-\tau_{t}\right)\left[1-l_{t}(\alpha)\right] w_{t}-q n_{t+1}(\alpha)-s_{t}(\alpha),\right. \\
& R_{t+1} s_{t}(\alpha)+\tau_{t+1} w_{t+1}\left(1-\bar{l}_{t+1}(\alpha)\right)\left[(1-\alpha) \bar{n}_{t+1}(\alpha) \frac{1-l_{t}(\alpha)}{1-\bar{l}_{t}(\alpha)}\right. \\
& \left.\left.+\alpha n_{t+1}(\alpha)\right], n_{t+1}(\alpha), l_{t}(\alpha)\right\}
\end{aligned}
$$

where the factor $\frac{1-l_{t}(\alpha)}{1-\bar{l}_{t}(\alpha)}$ would be replaced by 1 under a Beveridgean rule.

Employing the envelope theorem, the derivation with respect to $\alpha$ yields, after rearranging:

$$
\begin{aligned}
\frac{d V_{B i s}}{d \alpha}= & U_{2} \tau_{t+1} w_{t+1}\left\{\left(1-\bar{l}_{t+1}\right)\left[n_{t+1}-\bar{n}_{t+1} \frac{1-l_{t}}{1-\bar{l}_{t}}\right]\right. \\
& -\frac{\partial \bar{l}_{t+1}}{\partial \alpha}\left[(1-\alpha) \bar{n}_{t+1} \frac{1-l_{t}}{1-\bar{l}_{t}}+\alpha n_{t+1}\right] \\
& +\left(1-\bar{l}_{t+1}\right)(1-\alpha) \bar{n}_{t+1} \frac{1-l_{t}}{\left[1-\bar{l}_{t}\right]^{2}} \frac{\partial \bar{l}_{t}}{\partial \alpha} \\
& \left.+(1-\alpha)\left(1-\bar{l}_{t+1}\right) \frac{\partial \bar{n}_{t+1}}{\partial \alpha} \frac{1-l_{t}}{1-\bar{l}_{t}}\right\}
\end{aligned}
$$

and

$$
\begin{aligned}
\frac{d V_{B e v}}{d \alpha}= & U_{2} \tau_{t+1} w_{t+1}\left\{\left(1-\bar{l}_{t+1}\right)\left[n_{t+1}-\bar{n}_{t+1}\right]\right. \\
& -\frac{\partial \bar{l}_{t+1}}{\partial \alpha}\left[(1-\alpha) \bar{n}_{t+1}+\alpha n_{t+1}\right] \\
& \left.+(1-\alpha)\left(1-\bar{l}_{t+1}\right) \frac{\partial \bar{n}_{t+1}}{\partial \alpha} \frac{1-l_{t}}{1-\bar{l}_{t}}\right\}
\end{aligned}
$$

In the simple case of homogenous households the aggregate population growth factor is identical to the individual fertility factor: $\overline{n_{t}}=n_{t}$ in the equilibrium. Hence,

$$
\frac{d V}{d \alpha}(\alpha=1)=-U_{2} \tau_{t+1} w_{t+1} \bar{n}_{t+1} \frac{\partial \bar{l}_{t+1}}{\partial \alpha}
$$


Thus, if $\frac{\partial \bar{l}_{t}}{\partial \alpha}>0$ at $\alpha=1$, the optimum child factor is smaller than unity. Recalling Proposition 1, such a reaction can be expected if the price of a child becomes negative when the full pension is contingent on fertility. This condition tends to be satisfied if the size of the pension scheme, measured by the contribution rate $\tau$, is large and average fertility is small even at $\alpha=1$. Conversely, should $\frac{\partial \bar{l}_{t}}{\partial \alpha}<0$ at $\alpha=1$ hold, a higher utility level might be achieved by introducing a family allowance tax. Of course, this requires $\frac{\partial \bar{l}_{t}}{\partial \theta}<0$ at $(\alpha=1, \theta=0)$. The additional gain in lifetime utility then arises from a higher labor supply of other individuals. In contrast, the marginal impact via the fertility reaction is zero.

The result can be explained as follows. First, the increasing child factor changes the weights of the contribution-related pension and the fertilityrelated pension. Since individuals have the same number of children, the net effect of changing the composition is zero, as expressed by $U_{2} \tau_{t+1} w_{t+1}(1-$ $\left.\bar{l}_{t+1}\right)\left[n_{t+1}-\bar{n}_{t+1} \frac{1-l_{t}}{1-\bar{l}_{t}}\right]=0$.

Second, raising the child factor affects utility because the next contributor generation changes its labor supply per capita. Consequently, the contributions to finance the pensions of the present generation move in the same direction. The impact of the associated change in pensions on welfare is shown by

$$
-U_{2} \tau_{t+1} w_{t+1} \frac{\partial \bar{l}_{t+1}}{\partial \alpha}\left[(1-\alpha) \bar{n}_{t+1} \frac{1-l_{t}}{1-\bar{l}_{t}}+\alpha n_{t+1}\right] .
$$

Third, an effect arising only in the Bismarckian scheme, but not in the Beveridgean system, the general pension changes at a given pension fund level with varying claims by other people due to their labor supply reaction. This impact is captured by $U_{2} \tau_{t+1} w_{t+1}\left(1-\bar{l}_{t+1}\right)(1-\alpha) \bar{n}_{t+1} \frac{1-\bar{l}_{t}}{\left[1-\bar{l}_{t}\right]^{2}} \frac{\partial \bar{l}_{t}}{\partial \alpha}$.

Fourth, a higher child factor increases the number of future contributors to the general pay-as-you-go pension system and, therefore, the rate of return of this part of the system. This raises the utility of the present generation, as shown by $U_{2} \tau_{t+1} w_{t+1}(1-\alpha)\left(1-\bar{l}_{t+1}\right) \frac{\partial \bar{n}_{t+1}}{\partial \alpha} \frac{1-l_{t}}{1-\bar{l}_{t}}>0$. Since only the second effect survives if the share of general public pensions tends to zero, the labor supply reaction is crucial for evaluating the total marginal effect at $\alpha=1$.

As in Fenge and Meier (2003), setting the child factor to unity will not necessarily maximize lifetime utility of a representative household in the steady 
state. An increase of the child factor is associated with more heads of the future generation, raising the return to general social security contributions, but probably less wage income per head, reducing the return in both branches of the public pension system.

The child factor can be used to reduce the intra-generational externality, where the gains accrue to the general pensions. If the share of this general part becomes small, the impact on welfare will also go down. At the same time, the inter-generational externality, caused by children changing their working hours without taking into account the impact on their parents' pensions, cannot be overcome. This externality arises due to the realistic setting of wage-related contributions at a fixed rate. In contrast, should pensions be financed by lump-sum contributions, the optimum child factor in the absence of family allowances would be unity.

\section{Conclusions}

The main message of this paper is that fertility-related pensions and family allowances cannot be viewed as perfect substitutes. If there is some lump-sum benefit in the pension formula, the corresponding social security contributions will be perceived as taxes. While financing family allowances at a defined contribution rate towards the pension system will increase the tax load on labor, this does not happen if fertility-related pensions are introduced at the expense of general Beveridgean flat pensions. Due to the smaller distortion in the labor supply, the resulting welfare level will be higher with fertilityrelated pensions.

Further, the positive externality of having children for pay-as-you-go pension schemes should generally not be internalized by making the pension completely dependent on fertility. This result has to be traced back to the fact that an intergenerational externality exists in the pension scheme. Individuals do not take into account the impact of changing their labor supply on the parent generation. If labor supply falls with a higher child factor in the pension formula, the optimum share of fertility-related pensions remains below unity. In the opposite case, lifetime utility can still be increased by introducing a family allowance if households do not respond by increasing their demand for leisure.

An interesting extension of the current analysis would be to drop the assumption of a small open economy. Given a Beveridgean pension scheme, 
utilizing fertility-related pensions rather than child benefits will typically be associated with a higher labor supply and more saving per capita. It is not clear in advance how these changes affect the capital-labor ratio and factor prices in a closed economy. In addition, it is conceivable that differences in income and welfare will be even more accentuated if an endogenous growth framework is adopted.

Further, distributional aspects within generations have not been discussed. Introducing heterogeneity in fertility would imply that individuals are affected by policy measures encouraging fertility in an asymmetric fashion. It may then be asked under which circumstances a Pareto improvement is created without additional redistributive measures, and how such measures should be designed if there is a conflict of interest between childless individuals and parents. Incorporating both endogenous factor prices and heterogeneity in fertility would make it possible for childless people who are subsidizing others through fertility-related pensions or in family allowances to be compensated by an increase in the interest rate in the economy, as in Felderer and Ritzberger (1995). Nevertheless, we expect that the main arguments developed in this paper remain intact in such an extended framework.

\section{Appendix}

\section{A: Strict concavity of the objective function}

For strict concavity we have to show that

$$
U_{s s}<0, \operatorname{det}\left|\begin{array}{cc}
U_{s s} & U_{s n} \\
U_{n s} & U_{n n}
\end{array}\right|>0, \operatorname{det}\left|\begin{array}{ccc}
U_{s s} & U_{s n} & U_{s l} \\
U_{n s} & U_{n n} & U_{n l} \\
U_{l s} & U_{l n} & U_{l l}
\end{array}\right|<0
$$

Notice that

$$
\begin{gathered}
U_{s s}=U_{11}+R_{t+1}^{2} U_{22}<0 \\
U_{n n}=U_{11}\left(a_{t}-q\right)^{2}+U_{22} \tau_{t+1}^{2} w_{t+1}^{2}\left(1-\bar{l}_{t+1}\right)^{2} \alpha^{2}+U_{33}<0 \\
U_{s n}=-U_{11}\left(a_{t}-q\right)+R_{t+1} U_{22} \tau_{t+1} w_{t+1}\left(1-\bar{l}_{t+1}\right) \alpha,
\end{gathered}
$$




$$
\begin{gathered}
U_{l l}=U_{11}\left(1-\tau_{t}-\theta_{t}\right)^{2} w_{t}^{2}+U_{22}\left[\frac{\partial p_{t+1}}{\partial l_{t}}\right]^{2}+U_{44}<0 \\
U_{s l}=U_{11}\left(1-\tau_{t}-\theta_{t}\right) w_{t}+R_{t+1} U_{22} \frac{\partial p_{t+1}}{\partial l_{t}} \\
\begin{aligned}
& U_{n l}=-U_{11}\left(a_{t}-q\right)\left(1-\tau_{t}-\theta_{t}\right) w_{t}+U_{22} \tau_{t+1} w_{t+1}\left(1-\bar{l}_{t+1}\right) \alpha \frac{\partial p_{t+1}}{\partial l_{t}} \\
& \text { It follows that } \\
& U_{s s} U_{n n}-U_{s n} U_{n s}= U_{33}\left(U_{11}+R_{t+1}^{2} U_{22}\right) \\
&+U_{11} U_{22}\left[R_{t+1}\left(a_{t}-q\right)+\tau_{t+1} w_{t+1}\left(1-\bar{l}_{t+1}\right) \alpha\right]^{2} \\
&> 0
\end{aligned}
\end{gathered}
$$

and

$$
\begin{aligned}
& U_{s s}\left(U_{n n} U_{l l}-U_{n l} U_{l n}\right)-U_{s n}\left(U_{n s} U_{l l}-U_{n l} U_{l s}\right)+U_{s l}\left(U_{n s} U_{l n}-U_{n n} U_{l s}\right) \\
= & U_{s s}\left[U_{33} U_{l l}+U_{44}\left[U_{11}\left(a_{t}-q\right)^{2}+U_{22} \tau_{t+1}^{2} w_{t+1}^{2}\left(1-\bar{l}_{t+1}\right)^{2} \alpha^{2}\right]\right. \\
& \left.+U_{11} U_{22}\left[\left(a_{t}-q\right) \frac{\partial p_{t+1}}{\partial l_{t}}+\left(1-\tau_{t}-\theta_{t}\right) w_{t} \tau_{t+1} w_{t+1}\left(1-\bar{l}_{t+1}\right) \alpha\right]^{2}\right] \\
& -U_{s n}\left[U_{44} U_{n s}+U_{11} U_{22}\left[R_{t+1} \tau_{t+1} w_{t+1}\left(1-\bar{l}_{t+1}\right) \alpha\left(1-\tau_{t}-\theta_{t}\right)^{2} w_{t}^{2}\right.\right. \\
& -\left(a_{t}-q\right)\left[\frac{\partial p_{t+1}}{\partial l_{t}}\right]^{2}-\left(1-\tau_{t}-\theta_{t}\right) w_{t} \tau_{t+1} w_{t+1}\left(1-\bar{l}_{t+1}\right) \alpha \frac{\partial p_{t+1}}{\partial l_{t}} \\
& \left.\left.+R_{t+1} \frac{\partial p_{t+1}}{\partial l_{t}}\left(a_{t}-q\right)\left(1-\tau_{t}-\theta_{t}\right) w_{t}\right]\right] \\
& +U_{s l}\left[U_{33} U_{l s}+U_{11} U_{22}\left[-R_{t+1}\left(a_{t}-q\right)\left(1-\tau_{t}-\theta_{t}\right) w_{t} \tau_{t+1} w_{t+1}\left(1-\bar{l}_{t+1}\right) \alpha\right.\right. \\
& -\left(a_{t}-q\right) \tau_{t+1} w_{t+1}\left(1-\bar{l}_{t+1}\right) \alpha \frac{\partial p_{t+1}}{\partial l_{t}}-R_{t+1}\left(a_{t}-q\right)^{2} \frac{\partial p_{t+1}}{\partial l_{t}} \\
& \left.\left.-\left(1-\tau_{t}-\theta_{t}\right) w_{t} \tau_{t+1}^{2} w_{t+1}^{2}\left(1-\bar{l}_{t+1}\right)^{2} \alpha^{2}\right]\right] \\
= & U_{s s}\left[U_{33} U_{l l}+U_{44}\left[U_{11}\left(a_{t}-q\right)^{2}+U_{22} \tau_{t+1}^{2} w_{t+1}^{2}\left(1-\bar{l}_{t+1}\right)^{2} \alpha^{2}\right]\right] \\
& -U_{s n} U_{44} U_{n s}+U_{s l} U_{33} U_{l s} \\
= & U_{33}\left[U_{s s} U_{l l}+U_{l l} U_{s s}+U_{44} U_{11} U_{22}\left[\left(a_{t}-q\right) R_{t+1}-\tau_{t+1} w_{t+1}\left(1-\bar{l}_{t+1}\right) \alpha\right]^{2}\right. \\
< & 0 .
\end{aligned}
$$




\section{B: Proof of Proposition 1}

Proof. Applying the implicit function theorem to the set of first-order conditions (6) - (8) leads to

$$
\frac{\partial n}{\partial \alpha}=-\frac{\operatorname{det}\left[\begin{array}{ccc}
U_{s s} & U_{s \alpha} & U_{s l} \\
U_{n s} & U_{n \alpha} & U_{n l} \\
U_{l s} & U_{l \alpha} & U_{l l}
\end{array}\right]}{\operatorname{det}\left[\begin{array}{lll}
U_{s s} & U_{s n} & U_{s l} \\
U_{n s} & U_{n n} & U_{n l} \\
U_{l s} & U_{l n} & U_{l l}
\end{array}\right]}
$$

with

$$
\begin{gathered}
U_{s \alpha}=U_{22} R_{t+1} \tau_{t+1} w_{t+1}\left(1-\bar{l}_{t+1}\right)\left[n_{t+1}-\bar{n}_{t+1} \frac{1-l_{t}}{1-\bar{l}_{t}}\right] \\
\begin{array}{c}
U_{n \alpha}=U_{22} \tau_{t+1}^{2} w_{t+1}^{2}\left(1-\bar{l}_{t+1}\right)^{2} \alpha\left[n_{t+1}-\bar{n}_{t+1} \frac{1-l_{t}}{1-\bar{l}_{t}}\right] \\
+U_{2} \tau_{t+1} w_{t+1}\left(1-\bar{l}_{t+1}\right), \\
U_{l \alpha}=-U_{22} \tau_{t+1}^{2} w_{t+1}^{2}(1-\alpha) \bar{n}_{t+1} \frac{\left(1-\bar{l}_{t+1}\right)^{2}}{1-\bar{l}_{t}}\left[n_{t+1}-\bar{n}_{t+1} \frac{1-l_{t}}{1-\bar{l}_{t}}\right] \\
+U_{2} \tau_{t+1} w_{t+1} \bar{n}_{t+1} \frac{1-\bar{l}_{t+1}}{1-\bar{l}_{t}}
\end{array}
\end{gathered}
$$

under a Bismarckian scheme and

$$
\begin{gathered}
U_{s \alpha}=U_{22} R_{t+1} \tau_{t+1} w_{t+1}\left(1-\bar{l}_{t+1}\right)\left[n_{t+1}-\bar{n}_{t+1}\right], \\
U_{n \alpha}=U_{22} \tau_{t+1}^{2} w_{t+1}^{2}\left(1-\bar{l}_{t+1}\right)^{2} \alpha\left[n_{t+1}-\bar{n}_{t+1}\right] \\
+U_{2} \tau_{t+1} w_{t+1}\left(1-\bar{l}_{t+1}\right), \\
U_{l \alpha}=0,
\end{gathered}
$$


if the general pension is of the Beveridgean type.

The denominator on the RHS of equation (21) has a negative sign due to the strict concavity of the utility function with respect to the decision variables. In a population with identical households in each generation, $n_{t}=$ $\bar{n}_{t}$ and $l_{t}=\bar{l}_{t}$ hold in any symmetrical equilibrium. Hence, $U_{s \alpha}=0$ and $U_{n \alpha}>0$ are valid under each regime. $U_{l \alpha}>0$ holds in a Bismarckian scheme, while $U_{l \alpha}=0$ is true under the Beveridgean scheme. It turns out that

$$
\operatorname{sgn}\left[\frac{\partial n}{\partial \alpha}\right]=\operatorname{sgn}\left\{U_{n \alpha}\left[U_{s s} U_{l l}-U_{l s} U_{s l}\right]-U_{l \alpha}\left[U_{s s} U_{n l}-U_{n s} U_{s l}\right]\right\}
$$

in the Bismarckian case and

$$
\operatorname{sgn}\left[\frac{\partial n}{\partial \alpha}\right]=\operatorname{sgn}\left\{U_{n \alpha}\left[U_{s s} U_{l l}-U_{l s} U_{s l}\right]\right\}>0
$$

in the Beveridgean case, noting that $U_{s s} U_{l l}-U_{l s} U_{s l}>0$ is valid due to the strict concavity of the objective function. Further,

$$
\begin{aligned}
& U_{s s} U_{n l}-U_{n s} U_{s l} \\
= & U_{11} U_{22}\left[\left[\tau_{t+1} w_{t+1}\left(1-\bar{l}_{t+1}\right) \alpha+R_{t+1}\left(a_{t}-q\right)\right] \frac{\partial p_{t+1}}{\partial l_{t}}\right. \\
& \left.-\left(1-\tau_{t}-\theta_{t}\right) w_{t} R_{t+1}\left[\tau_{t+1} w_{t+1}\left(1-\bar{l}_{t+1}\right) \alpha+R_{t+1}\left(a_{t}-q\right)\right]\right] \\
= & U_{11} U_{22}\left[\tau_{t+1} w_{t+1}\left(1-\bar{l}_{t+1}\right) \alpha+R_{t+1}\left(a_{t}-q\right)\right] \\
& \cdot\left[\frac{\partial p_{t+1}}{\partial l_{t}}-\left(1-\tau_{t}-\theta_{t}\right) w_{t} R_{t+1}\right] .
\end{aligned}
$$

Recalling that $\frac{\partial p_{t+1}}{\partial l_{t}}<0$ in a Bismarckian scheme, this expression is negative if, and only if, $\tau_{t+1} w_{t+1}\left(1-\bar{l}_{t+1}\right) \alpha+R_{t+1}\left(a_{t}-q\right)>0$ holds, that is, the total monetary benefit of having a child exceeds the cost of raising this child. The former is given by the sum of the additional fertility-related pension and the child benefit, where payments in different periods are made comparable by 
using the interest factor $R_{t+1}$. Evaluating the derivatives yields

$$
\begin{aligned}
& U_{n \alpha}\left[U_{s s} U_{l l}-U_{l s} U_{s l}\right]-U_{l \alpha}\left[U_{s s} U_{n l}-U_{n s} U_{s l}\right] \\
= & U_{2} \tau_{t+1} w_{t+1}\left(1-\bar{l}_{t+1}\right) \\
& \cdot\left[\left[U_{11}+R_{t+1}^{2} U_{22}\right] U_{44}+U_{11} U_{22}\left[\frac{\partial p_{t+1}}{\partial l_{t}}-\left(1-\tau_{t}-\theta_{t}\right) w_{t} R_{t+1}\right]\right] \\
& -U_{2} \tau_{t+1} w_{t+1} \bar{n}_{t+1} \frac{1-\bar{l}_{t+1}}{1-\bar{l}_{t}} U_{11} U_{22} \\
& \cdot\left[\tau_{t+1} w_{t+1}\left(1-\bar{l}_{t+1}\right) \alpha+R_{t+1}\left(a_{t}-q\right)\right]\left[\frac{\partial p_{t+1}}{\partial l_{t}}-\left(1-\tau_{t}-\theta_{t}\right) w_{t} R_{t+1}\right] \\
= & U_{2} \tau_{t+1} w_{t+1}\left(1-\bar{l}_{t+1}\right)\left[\left[U_{11}+R_{t+1}^{2} U_{22}\right] U_{44}\right. \\
& -U_{11} U_{22}\left[\frac{\partial p_{t+1}}{\partial l_{t}}-\left(1-\tau_{t}-\theta_{t}\right) w_{t} R_{t+1}\right] \frac{1}{1-\bar{l}_{t}} \\
& \cdot\left[\tau_{t+1} w_{t+1} \bar{n}_{t+1}\left(1-\bar{l}_{t+1}\right)+\left(1-\tau_{t}-\theta_{t}\right)\left(1-\bar{l}_{t}\right) w_{t} R_{t+1}\right. \\
& \left.\left.+R_{t+1}\left(a_{t}-q\right) \bar{n}_{t+1}\right]\right] \\
= & U_{2} \tau_{t+1} w_{t+1}\left(1-\bar{l}_{t+1}\right)\left[\left[U_{11}+R_{t+1}^{2} U_{22}\right] U_{44}\right. \\
& \left.-U_{11} U_{22}\left[\frac{\partial p_{t+1}}{\partial l_{t}}-\left(1-\tau_{t}-\theta_{t}\right) w_{t} R_{t+1}\right] \frac{1}{1-\bar{l}_{t}}\left[R_{t+1} c_{t}+z_{t+1}\right]\right] \\
> & 0 .
\end{aligned}
$$

Hence, $\frac{\partial n}{\partial \alpha}>0$ also holds with a Bismarckian pension scheme.

The derivative of leisure with respect to $\alpha$ is given by

$$
\frac{\partial l}{\partial \alpha}=-\frac{\operatorname{det}\left[\begin{array}{ccc}
U_{s s} & U_{s n} & U_{s \alpha} \\
U_{n s} & U_{n n} & U_{n \alpha} \\
U_{l s} & U_{l n} & U_{l \alpha}
\end{array}\right]}{\operatorname{det}\left[\begin{array}{lll}
U_{s s} & U_{s n} & U_{s l} \\
U_{n s} & U_{n n} & U_{n l} \\
U_{l s} & U_{l n} & U_{l l}
\end{array}\right]}
$$

This implies

$$
\operatorname{sgn}\left[\frac{\partial l}{\partial \alpha}\right]=\operatorname{sgn}\left\{U_{l \alpha}\left[U_{s s} U_{n n}-U_{s n} U_{n s}\right]-U_{n \alpha}\left[U_{s s} U_{l n}-U_{l s} U_{s n}\right]\right\}
$$

if a Bismarckian scheme is in place and

$$
\operatorname{sgn}\left[\frac{\partial l}{\partial \alpha}\right]=\operatorname{sgn}\left\{-U_{n \alpha}\left[U_{s s} U_{l n}-U_{l s} U_{s n}\right]\right\}
$$


under a Beveridgean regime. Notice that $U_{s s} U_{n n}-U_{s n} U_{n s}>0$ holds due to the strict concavity of the objective function and $\operatorname{sgn}\left[U_{s s} U_{l n}-U_{l s} U_{s n}\right]=$ $-\operatorname{sgn}\left[\tau_{t+1} w_{t+1}\left(1-\bar{l}_{t+1}\right) \alpha+R_{t+1}\left(a_{t}-q\right)\right]$, as shown above. Evaluating the derivatives yields

$$
\begin{aligned}
& U_{l \alpha}\left[U_{s s} U_{n n}-U_{s n} U_{n s}\right]-U_{n \alpha}\left[U_{s s} U_{l n}-U_{l s} U_{s n}\right] \\
= & U_{2} \tau_{t+1} w_{t+1} \bar{n}_{t+1} \frac{1-\bar{l}_{t+1}}{1-\bar{l}_{t}} \cdot\left[U_{33}\left(U_{11}+R_{t+1}^{2} U_{22}\right)\right. \\
& \left.+U_{11} U_{22}\left[R_{t+1}\left(a_{t}-q\right)+\tau_{t+1} w_{t+1}\left(1-\bar{l}_{t+1}\right) \alpha\right]^{2}\right] \\
& +U_{2} \tau_{t+1} w_{t+1}\left(1-\bar{l}_{t+1}\right) \\
& \cdot U_{11} U_{22}\left[(1-\alpha) \tau_{t+1} w_{t+1} \bar{n}_{t+1} \frac{1-\bar{l}_{t+1}}{1-\bar{l}_{t}}+\left(1-\tau_{t}-\theta_{t}\right) w_{t} R_{t+1}\right] \\
& \cdot\left[R_{t+1}\left(a_{t}-q\right)+\tau_{t+1} w_{t+1}\left(1-\bar{l}_{t+1}\right) \alpha\right] \\
= & U_{2} \tau_{t+1} w_{t+1} \bar{n}_{t+1} \frac{1-\bar{l}_{t+1}}{1-\bar{l}_{t}} U_{33}\left(U_{11}+R_{t+1}^{2} U_{22}\right) \\
& +U_{2} \tau_{t+1} w_{t+1}\left(1-\bar{l}_{t+1}\right) U_{11} U_{22} \frac{1}{1-\bar{l}_{t}} \\
& \cdot\left[R_{t+1}\left(a_{t}-q\right)+\tau_{t+1} w_{t+1}\left(1-\bar{l}_{t+1}\right) \alpha\right] \\
& \cdot\left[\bar{n}_{t+1} R_{t+1}\left(a_{t}-q\right)+\tau_{t+1} w_{t+1} \bar{n}_{t+1}\left(1-\bar{l}_{t+1}\right)\right. \\
& \left.+\left(1-\tau_{t}-\theta_{t}\right) w_{t} R_{t+1}\left(1-\bar{l}_{t}\right)\right] \\
= & U_{2} \tau_{t+1} w_{t+1} \bar{n}_{t+1} \frac{1-\bar{l}_{t+1}}{1-\bar{l}_{t}} U_{33}\left(U_{11}+R_{t+1}^{2} U_{22}\right) \\
& +U_{2} \tau_{t+1} w_{t+1}\left(1-\bar{l}_{t+1}\right) U_{11} U_{22} \frac{1}{1-\bar{l}_{t}} \\
& \cdot\left[R_{t+1}\left(a_{t}-q\right)+\tau_{t+1} w_{t+1}\left(1-\bar{l}_{t+1}\right) \alpha\right]\left[R_{t+1} c_{t}+z_{t+1}\right] .
\end{aligned}
$$

Hence, it follows that $R_{t+1}\left(a_{t}-q\right)+\tau_{t+1} w_{t+1}\left(1-\bar{l}_{t+1}\right) \alpha>0$ is sufficient to arrive at $\frac{\partial l}{\partial \alpha}>0$ under a Bismarckian regime.

\section{C: Proof of Proposition 2}

Applying the implicit function theorem to the set of first-order conditions (6) - (8) leads to 


$$
\frac{\partial n}{\partial \theta}=-\frac{\operatorname{det}\left[\begin{array}{ccc}
U_{s s} & U_{s \theta} & U_{s l} \\
U_{n s} & U_{n \theta} & U_{n l} \\
U_{l s} & U_{l \theta} & U_{l l}
\end{array}\right]}{\operatorname{det}\left[\begin{array}{lll}
U_{s s} & U_{s n} & U_{s l} \\
U_{n s} & U_{n n} & U_{n l} \\
U_{l s} & U_{l n} & U_{l l}
\end{array}\right]}
$$

and

$$
\frac{\partial l}{\partial \theta}=-\frac{\operatorname{det}\left[\begin{array}{ccc}
U_{s s} & U_{s n} & U_{s \theta} \\
U_{n s} & U_{n n} & U_{n \theta} \\
U_{l s} & U_{l n} & U_{l \theta}
\end{array}\right]}{\operatorname{det}\left[\begin{array}{lll}
U_{s s} & U_{s n} & U_{s l} \\
U_{n s} & U_{n n} & U_{n l} \\
U_{l s} & U_{l n} & U_{l l}
\end{array}\right]} .
$$

Under both pension regimes we have

$$
\begin{gathered}
U_{s \theta}=U_{11}\left(\left(1-l_{t}\right) w_{t}-\frac{n_{t+1}}{\bar{n}_{t+1}} w_{t}\left(1-\bar{l}_{t}\right)\right) \\
U_{n \theta}=U_{1} \frac{w_{t}\left(1-\bar{l}_{t}\right)}{\bar{n}_{t+1}}+U_{11} \frac{\theta_{t} w_{t}\left(1-\bar{l}_{t}\right)}{\bar{n}_{t+1}}\left(-\left(1-l_{t}\right) w_{t}+\frac{n_{t+1}}{\bar{n}_{t+1}} w_{t}\left(1-\bar{l}_{t}\right)\right) \\
U_{l \theta}=U_{1} w_{t}+U_{11}\left(1-\tau_{t}-\theta_{t}\right) w_{t}\left(\left(1-l_{t}\right) w_{t}-\frac{n_{t+1}}{\bar{n}_{t+1}} w_{t}\left(1-\bar{l}_{t}\right)\right)
\end{gathered}
$$

Again, in a homogenous population with identical households in each generation, $n_{t}=\bar{n}_{t}$ and $l_{t}=\bar{l}_{t}$ holds in equilibrium. Hence, $U_{s \theta}=0, U_{n \theta}>0$, and $U_{l \theta}>0$. Due to the strict concavity of the objective function, it follows that

$$
\operatorname{sgn}\left[\frac{\partial n}{\partial \theta}\right]=\operatorname{sgn}\left\{U_{n \theta}\left[U_{s s} U_{l l}-U_{s l} U_{l s}\right]-U_{l \theta}\left[U_{s s} U_{n l}-U_{n s} U_{s l}\right]\right\}
$$

and

$$
\operatorname{sgn}\left[\frac{\partial l}{\partial \theta}\right]=\operatorname{sgn}\left\{U_{l \theta}\left[U_{s s} U_{n n}-U_{s n} U_{n s}\right]-U_{n \theta}\left[U_{s s} U_{l n}-U_{l s} U_{s n}\right]\right\} .
$$


Evaluating the derivatives shows that

$$
\begin{aligned}
& U_{n \theta}\left[U_{s s} U_{l l}-U_{s l} U_{l s}\right]-U_{l \theta}\left[U_{s s} U_{n l}-U_{n s} U_{s l}\right] \\
= & U_{1} \frac{w_{t}\left(1-\bar{l}_{t}\right)}{\bar{n}_{t+1}}\left[U_{44}\left(U_{11}+R_{t+1}^{2} U_{22}\right)\right. \\
& \left.+U_{11} U_{22}\left[\frac{\partial p_{t+1}}{\partial l_{t}}-\left(1-\tau_{t}-\theta_{t}\right) w_{t} R_{t+1}\right]^{2}\right] \\
& -U_{1} w_{t} U_{11} U_{22}\left[\frac{\partial p_{t+1}}{\partial l_{t}}-\left(1-\tau_{t}-\theta_{t}\right) w_{t} R_{t+1}\right] \\
& \cdot\left[R_{t+1}\left(a_{t}-q\right)+\tau_{t+1} w_{t+1}\left(1-\bar{l}_{t+1}\right) \alpha\right] \\
= & U_{1} \frac{w_{t}\left(1-\bar{l}_{t}\right)}{\bar{n}_{t+1}} U_{44}\left[U_{11}+R_{t+1}^{2} U_{22}\right] \\
& -U_{1} U_{11} U_{22} \frac{w_{t}}{\bar{n}_{t+1}}\left[\frac{\partial p_{t+1}}{\partial l_{t}}-\left(1-\tau_{t}-\theta_{t}\right) w_{t} R_{t+1}\right] \\
& \cdot\left[\left(1-\bar{l}_{t}\right)\left[\left(1-\tau_{t}-\theta_{t}\right) w_{t} R_{t+1}-\frac{\partial p_{t+1}}{\partial l_{t}}\right]\right. \\
& \left.+R_{t+1} \bar{n}_{t+1}\left(a_{t}-q\right)+\tau_{t+1} w_{t+1} \bar{n}_{t+1}\left(1-\bar{l}_{t+1}\right) \alpha\right]
\end{aligned}
$$

Notice that

$$
\begin{aligned}
& {\left[\left(1-\bar{l}_{t}\right)\left[\left(1-\tau_{t}-\theta_{t}\right) w_{t} R_{t+1}-\frac{\partial p_{t+1}}{\partial l_{t}}\right]\right.} \\
& \left.+R_{t+1} \bar{n}_{t+1}\left(a_{t}-q\right)+\tau_{t+1} w_{t+1} \bar{n}_{t+1}\left(1-\bar{l}_{t+1}\right) \alpha\right] \\
= & R_{t+1} c_{t}+z_{t+1}
\end{aligned}
$$

under a Bismarckian pension scheme, implying that $\frac{\partial n}{\partial \theta}>0$, while

$$
\begin{aligned}
& {\left[\left(1-\bar{l}_{t}\right)\left[\left(1-\tau_{t}-\theta_{t}\right) w_{t} R_{t+1}-\frac{\partial p_{t+1}}{\partial l_{t}}\right]\right.} \\
&\left.+R_{t+1} \bar{n}_{t+1}\left(a_{t}-q\right)+\tau_{t+1} w_{t+1} \bar{n}_{t+1}\left(1-\bar{l}_{t+1}\right) \alpha\right] \\
&=R_{t+1} c_{t}+z_{t+1}-\tau_{t+1} w_{t+1} \bar{n}_{t+1}\left(1-\bar{l}_{t+1}\right)(1-\alpha)
\end{aligned}
$$

in a Beveridgean system. In the latter case, $R_{t+1} c_{t}+z_{t+1}-\tau_{t+1} w_{t+1} \bar{n}_{t+1}(1-$ $\left.\bar{l}_{t+1}\right)(1-\alpha) \geq 0$ is sufficient to guarantee $\frac{\partial n}{\partial \theta}>0$. 
Further,

$$
\begin{aligned}
& U_{l \theta}\left[U_{s s} U_{n n}-U_{s n} U_{n s}\right]-U_{n \theta}\left[U_{s s} U_{l n}-U_{l s} U_{s n}\right] \\
= & U_{1} w_{t}\left[U_{33}\left[U_{11}+R_{t+1}^{2} U_{22}\right]\right. \\
& \left.+U_{11} U_{22}\left[R_{t+1}\left(a_{t}-q\right)+\tau_{t+1} w_{t+1}\left(1-\bar{l}_{t+1}\right) \alpha\right]^{2}\right] \\
& -U_{1} \frac{w_{t}\left(1-\bar{l}_{t}\right)}{\bar{n}_{t+1}} U_{11} U_{22}\left[\frac{\partial p_{t+1}}{\partial l_{t}}-\left(1-\tau_{t}-\theta_{t}\right) w_{t} R_{t+1}\right] \\
& \cdot\left[R_{t+1}\left(a_{t}-q\right)+\tau_{t+1} w_{t+1}\left(1-\bar{l}_{t+1}\right) \alpha\right] \\
= & U_{1} w_{t} U_{33}\left[U_{11}+R_{t+1}^{2} U_{22}\right] \\
& +U_{1} \frac{w_{t}}{\bar{n}_{t+1}} U_{11} U_{22}\left[R_{t+1}\left(a_{t}-q\right)+\tau_{t+1} w_{t+1}\left(1-\bar{l}_{t+1}\right) \alpha\right] \\
& \cdot\left[\bar{n}_{t+1} R_{t+1}\left(a_{t}-q\right)+\tau_{t+1} w_{t+1} \bar{n}_{t+1}\left(1-\bar{l}_{t+1}\right) \alpha\right. \\
& \left.+\left(1-\tau_{t}-\theta_{t}\right)\left(1-\bar{l}_{t}\right) w_{t} R_{t+1}-\left(1-\bar{l}_{t}\right) \frac{\partial p_{t+1}}{\partial l_{t}}\right]
\end{aligned}
$$

Recalling (42), it follows that $\frac{\partial l}{\partial \theta}>0$ holds if $R_{t+1}\left(a_{t}-q\right)+\tau_{t+1} w_{t+1}(1-$ $\left.\bar{l}_{t+1}\right) \alpha \geq 0$. Under a Beveridgean scheme, $\frac{\partial l}{\partial \theta}>0$ is also valid if $R_{t+1}\left(a_{t}-q\right)+$ $\tau_{t+1} w_{t+1}\left(1-\bar{l}_{t+1}\right) \alpha<0$ and $R_{t+1} c_{t}+z_{t+1}-\tau_{t+1} w_{t+1} \bar{n}_{t+1}\left(1-\bar{l}_{t+1}\right)(1-\alpha) \leq 0$ hold, where (43) is taken into account.

\section{D: Example with $\frac{\partial n}{\partial \theta}<0$}

Consider a Cobb-Douglas utility function $u=\beta_{1} \ln c_{t}+\beta_{2} \ln z_{t+1}+\beta_{3} n_{t+1}+$ $\beta_{4} l_{t}$ with $\beta_{i} \in(0,1)$ and $\beta_{1}+\beta_{2}+\beta_{3}+\beta_{4}=1$. Let $I:=\left(1-\tau_{t}-\theta_{t}\right) w_{t}+$ $\frac{\tau_{t+1} w_{t+1}\left(1-\bar{l}_{t+1}\right)}{R_{t+1}}(1-\alpha) \bar{n}_{t+1}$ denote lifetime income. The demand functions satisfy $c_{t}=\beta_{1} I, \frac{z_{t+1}}{R_{t+1}}=\beta_{2} I, n_{t+1}\left(q-a_{t}-\frac{\alpha \tau_{t+1} w_{t+1}\left(1-\bar{l}_{t+1}\right)}{R_{t+1}}\right)=\beta_{3} I$, and $l_{t}\left(1-\tau_{t}-\theta_{t}\right) w_{t}=\beta_{4} I$.

Assuming a stationary state, time subscripts can be omitted. It follows 
from (41) and (43) that under a Beveridgean scheme with $\alpha=1$,

$$
\begin{aligned}
& {\left[U_{n \theta}\left[U_{s s} U_{l l}-U_{s l} U_{l s}\right]-U_{l \theta}\left[U_{s s} U_{n l}-U_{n s} U_{s l}\right]\right] w /\left(n U_{1}\right) } \\
= & (1-l) \frac{\beta_{4}}{l^{2}}\left[\frac{\beta_{1}}{c^{2}}+\frac{R^{2} \beta_{2}}{z^{2}}\right]+\frac{\beta_{1}}{c^{2}} \frac{R^{2} \beta_{2}}{z^{2}}(1-\tau-\theta) w R \\
& \cdot[R c+z-\tau w n(1-l)] \\
= & (1-l) \frac{[(1-\tau-\theta) w]^{2}}{\beta_{4} I^{2}}\left[\frac{1}{\beta_{1} I^{2}}+\frac{1}{\beta_{2} I^{2}}\right] \\
& +\frac{(1-\tau-\theta) w R}{\beta_{1} I^{2} \beta_{2} I^{2}}\left[R\left(\beta_{1}+\beta_{2}\right) I-\tau w \frac{\beta_{3} I}{q-a}(1-l)\right] .
\end{aligned}
$$

This implies

$$
\begin{aligned}
\operatorname{sgn}\left[\frac{\partial n}{\partial \theta}\right]= & \operatorname{sgn}\left[(1-l)(1-\tau-\theta) w\left(\beta_{1}+\beta_{2}\right)\right. \\
& \left.+\beta_{4} R^{2}\left(\beta_{1}+\beta_{2}\right) I-\beta_{4} \tau w R \frac{\beta_{3} I}{q-a}(1-l)\right] .
\end{aligned}
$$

Setting $\beta_{1}$ and $\beta_{2}$ close to zero while having $\beta_{3}$ and $\beta_{4}$ sufficiently large so that $l$ is not close to unity, and considering the situation with $\theta=a=0$, then generates $\frac{\partial n}{\partial \theta}<0$.

\section{E: Proof of Proposition 4}

Let $I:=\left(1-\tau_{t}-\theta_{t}\right) w_{t}+\frac{\tau_{t+1} w_{t+1}\left(1-\bar{l}_{t+1}\right)}{R_{t+1}}(1-\alpha) \bar{n}_{t+1}$ denote lifetime income, where the prices of youth consumption, old age consumption, children, and leisure are given by $P_{c}:=1, P_{z}:=\frac{1}{R_{t+1}}, P_{n}:=q-\frac{\theta_{t} w_{t}\left(1-\bar{l}_{t}\right)}{\bar{n}_{t+1}}-$ $\alpha \frac{\tau_{t+1} w_{t+1}\left(1-\bar{l}_{t+1}\right)}{R_{t+1}}, P_{l}:=\left(1-\tau_{t}-\theta_{t}\right) w_{t}$, respectively. The price vector is denoted by $P:=\left(P_{c}, P_{z}, P_{n}, P_{l}\right)$. The indirect utility function is given by

$$
v(I, P)=u\left(c^{*}(I, P), z^{*}(I, P), n^{*}(I, P), l^{*}(I, P)\right) .
$$


Its derivatives with respect to the two policy instruments have to take into account the impacts on demand per capita for leisure and children:

$$
\begin{aligned}
\frac{\partial v}{\partial \alpha}= & \frac{\partial v}{\partial I}\left[\frac{\partial I}{\partial \alpha}+\frac{\partial I}{\partial \bar{l}_{t+1}} \frac{\partial \bar{l}_{t+1}}{\partial \alpha}+\frac{\partial I}{\partial \bar{n}_{t+1}} \frac{\partial \bar{n}_{t+1}}{\partial \alpha}\right] \\
& +\frac{\partial v}{\partial P_{n}}\left[\frac{\partial P_{n}}{\partial \alpha}+\frac{\partial P_{n}}{\partial \bar{l}_{t}} \frac{\partial \bar{l}_{t}}{\partial \alpha}+\frac{\partial P_{n}}{\partial \bar{l}_{t+1}} \frac{\partial \bar{l}_{t+1}}{\partial \alpha}+\frac{\partial P_{n}}{\partial \bar{n}_{t+1}} \frac{\partial \bar{n}_{t+1}}{\partial \alpha}\right], \\
\frac{\partial v}{\partial \theta}= & \frac{\partial v}{\partial I}\left[\frac{\partial I}{\partial \theta}+\frac{\partial I}{\partial \bar{l}_{t+1}} \frac{\partial \bar{l}_{t+1}}{\partial \theta}+\frac{\partial I}{\partial \bar{n}_{t+1}} \frac{\partial \bar{n}_{t+1}}{\partial \theta}\right] \\
& +\frac{\partial v}{\partial P_{n}}\left[\frac{\partial P_{n}}{\partial \theta}+\frac{\partial P_{n}}{\partial \bar{l}_{t}} \frac{\partial \bar{l}_{t}}{\partial \theta}+\frac{\partial P_{n}}{\partial \bar{l}_{t+1}} \frac{\partial \bar{l}_{t+1}}{\partial \theta}+\frac{\partial P_{n}}{\partial \bar{n}_{t+1}} \frac{\partial \bar{n}_{t+1}}{\partial \theta}\right] \\
& +\frac{\partial v}{\partial P_{l}} \frac{\partial P_{l}}{\partial \theta} .
\end{aligned}
$$

According to Roy's theorem we have $n_{t+1}=-\frac{\partial v}{\partial P_{n}} / \frac{\partial v}{\partial I}$ and $l_{t}=-\frac{\partial v}{\partial P_{l}} /$ $\frac{\partial v}{\partial I}$. Notice that at the symmetrical equilibrium in which $n_{t+1}=\bar{n}_{t+1}=n$ and $l_{t}=\bar{l}_{t}=l$,

$$
\begin{aligned}
\frac{\partial I}{\partial \alpha}-n \frac{\partial P_{n}}{\partial \alpha} & =0 \\
\frac{\partial I}{\partial \theta}-n \frac{\partial P_{n}}{\partial \theta}-l \frac{\partial P_{l}}{\partial \theta} & =0
\end{aligned}
$$

hold. Thus we arrive at

$$
\begin{aligned}
\frac{\frac{\partial v}{\partial \alpha}}{\frac{\partial v}{\partial I}=} & \frac{\partial I}{\partial \bar{l}_{t+1}} \frac{\partial \bar{l}_{t+1}}{\partial \alpha}+\frac{\partial I}{\partial \bar{n}_{t+1}} \frac{\partial \bar{n}_{t+1}}{\partial \alpha} \\
& -n\left[\frac{\partial P_{n}}{\partial \bar{l}_{t}} \frac{\partial \bar{l}_{t}}{\partial \alpha}+\frac{\partial P_{n}}{\partial \bar{l}_{t+1}} \frac{\partial \bar{l}_{t+1}}{\partial \alpha}+\frac{\partial P_{n}}{\partial \bar{n}_{t+1}} \frac{\partial \bar{n}_{t+1}}{\partial \alpha}\right] \\
\frac{\partial v}{\partial \theta}= & \frac{\partial I}{\partial \bar{l}_{t+1}} \frac{\partial \bar{l}_{t+1}}{\partial \theta}+\frac{\partial I}{\partial \bar{n}_{t+1}} \frac{\partial \bar{n}_{t+1}}{\partial \theta} \\
& -n\left[\frac{\partial P_{n}}{\partial \bar{l}_{t}} \frac{\partial \bar{l}_{t}}{\partial \theta}+\frac{\partial P_{n}}{\partial \bar{l}_{t+1}} \frac{\partial \bar{l}_{t+1}}{\partial \theta}+\frac{\partial P_{n}}{\partial \bar{n}_{t+1}} \frac{\partial \bar{n}_{t+1}}{\partial \theta}\right]
\end{aligned}
$$

Notice that $\frac{\partial n}{\partial \alpha}>0, \frac{\partial I}{\partial \bar{l}_{t+1}}<0, \frac{\partial P_{n}}{\partial \bar{l}_{t}} \geq 0$, and $\frac{\partial P_{n}}{\partial \bar{l}_{t+1}} \geq 0$ hold. If $\frac{\partial n}{\partial \theta}>0$ is valid at the margin, it remains to be shown that $\frac{\partial l_{t}}{\partial \theta}>\kappa \frac{\partial l_{t}}{\partial \alpha}$ is met, where 
$\kappa>0$ is defined by $\frac{\partial n_{t+1}}{\partial \theta}=\kappa \frac{\partial n_{t+1}}{\partial \alpha}$. Increasing $\alpha$ and decreasing $\theta$ at the same time so as to keep fertility constant will then yield a higher indirect utility level via the falling demand for leisure. Accordingly, should $\frac{\partial n}{\partial \theta}<0$ and $\frac{\partial l_{t}}{\partial \theta}>\kappa \frac{\partial l_{t}}{\partial \alpha}$ with $\kappa<0$ hold, an interior optimum with $\alpha>0$ and $\theta>0$ cannot exist. Reducing both $\alpha$ and $\theta$ so as to keep fertility constant again increases welfare due to a rising labor supply. Last, it should be noticed that an optimum policy mix with $\theta>0$ can never be characterized by $\frac{\partial n}{\partial \theta}=0$ at the margin. According to Proposition 2, such a situation implies $\frac{\partial l}{\partial \theta}>0$ and, therefore, $\frac{\partial v}{\partial \theta}<0$.

Following the proofs of the Propositions 1 and 2, it turns out that

$$
\kappa=\frac{U_{n \theta}}{U_{n \alpha}}-\frac{U_{l \theta}\left[U_{s s} U_{n l}-U_{n s} U_{s l}\right]}{U_{n \alpha}\left[U_{s s} U_{l l}-U_{l s} U_{s l}\right]}
$$

Thus, it has to be verified that

$$
\begin{gathered}
U_{l \theta}\left[U_{s s} U_{n n}-U_{n s} U_{n s}\right]-U_{n \theta}\left[U_{s s} U_{n l}-U_{n s} U_{s l}\right] \\
>-U_{n \theta}\left[U_{s s} U_{n l}-U_{n s} U_{s l}\right]+U_{l \theta} \frac{\left[U_{s s} U_{n l}-U_{n s} U_{s l}\right]^{2}}{U_{s s} U_{l l}-U_{l s} U_{s l}}
\end{gathered}
$$

holds. Since $U_{s s} U_{l l}-U_{l s} U_{s l}>0$ is a consequence of the strict concavity of the objective function, the inequality is equivalent to

$$
\begin{aligned}
& {\left[U_{s s} U_{n n}-U_{n s} U_{n s}\right]\left[U_{s s} U_{l l}-U_{l s} U_{s l}\right]-\left[U_{s s} U_{n l}-U_{n s} U_{s l}\right]^{2} } \\
= & U_{s s} \operatorname{det}\left[\begin{array}{ccc}
U_{s s} & U_{s n} & U_{s l} \\
U_{n s} & U_{n n} & U_{n l} \\
U_{l s} & U_{l n} & U_{l l}
\end{array}\right] \\
> & 0 .
\end{aligned}
$$

The last inequality is true because both $U_{s s}<0$ and $\operatorname{det}\left[\begin{array}{ccc}U_{s s} & U_{s n} & U_{s l} \\ U_{n s} & U_{n n} & U_{n l} \\ U_{l s} & U_{l n} & U_{l l}\end{array}\right]<$ 0 are again implied by the strict concavity of the objective function.

It remains to be shown that the optimum is never characterized by $\left(\alpha_{0}\right.$, $\left.\theta_{0}\right)$ with $\alpha_{0}=0, \theta_{0}>0$ and $\frac{\partial n}{\partial \theta}<0$. Should $\frac{\partial n}{\partial \theta} \leq 0$ hold throughout the range $\left(0, \theta_{0}\right)$, we have $n(\alpha=0, \theta=0)>n\left(\alpha=0, \theta=\theta_{0}\right)$ and $l(\alpha=$ $0, \theta=0)<l\left(\alpha=0, \theta=\theta_{0}\right)$. But then the average consumption vector at 
$\left(\alpha_{\mathbf{0}}, \theta_{\mathbf{0}}\right)$, that is, $(\bar{c}, \bar{z}, \bar{n}, \bar{l})\left(\alpha_{\mathbf{0}}, \theta_{\mathbf{0}}\right)$, is also feasible for a deviating household at $(\alpha=0, \theta=0)$, thus creating a budget surplus. Conversely, if we have $\frac{\partial n}{\partial \theta}>0$ for some $\theta$, it is again possible to trade off $\alpha$ and $\theta$ against each other to arrive at a situation with $\alpha_{1}>0, \theta_{1}=0$ where $n\left(\alpha_{1}, \theta_{1}\right) \geq n\left(\alpha_{0}, \theta_{0}\right)$ and $l\left(\alpha_{1}, \theta_{1}\right)<l\left(\alpha_{0}, \theta_{0}\right)$. Again, the choice of $(\bar{c}, \bar{z}, \bar{n}, \bar{l})\left(\alpha_{0}, \theta_{0}\right)$ would be associated with a budget surplus. 


\section{References}

Aaron, H., 1966. The social insurance paradox. Canadian Journal of Economics and Political Science 32, 371-374.

Ahn, N., Mira, P., 2002. A note on the changing relationship between fertility and female employment rates in developed countries. Journal of Population Economics 15, 667-682.

Cigno, A., Casolare, L., Rosati, F.C., 2003. The impact of social security on saving and fertility in Germany. FinanzArchiv 59, 189-211.

Cigno, A., Luporini, A., 2003. Optimal policy towards families with different amounts of social capital in the presence of asymmetric information and stochastic fertility. Paper presented at the CESifo Venice Summer Institute 2003.

Cigno, A., Rosati, F.C., 1996. Jointly determined saving and fertility behaviour: theory, and estimates for Germany, Italy, UK and USA. European Economic Review 40, 1561-1589.

Felderer, B., Ritzberger, K., 1995. Family allowances as welfare improvements. Journal of Economics 61, 11-33.

Fenge, R., Meier, V., 2003. Pensions and fertility incentives. CESifo Working Paper No. 879, Munich.

Kögel, T., 2002. Did the association between fertility and female employment within OECD countries really change its sign? Working Paper, Max Planck Institute for Demographic Research, Rostock.

Kolmar, M., 1997. Intergenerational redistribution in a small open economy with endogenous fertility. Journal of Population Economics 10, 335-356.

Kolmar, M., 2001. Optimal intergenerational redistribution in a two-country model with endogenous fertility. Public Choice 106, 23-51.

Peters, W., 1995. Public pensions, family allowances and endogenous demographic change. Journal of Population Economics 8, 161-183.

Sinn, H.-W., 2001. The value of children and immigrants in a pay-as-you-go pension system: a proposal for a transition to a funded system. ifo Studien $47,77-94$.

van Groezen, B., Leers, T., Meijdam, L., 2000. Family size, looming demographic changes and the efficiency of social security reform. CentER Working Paper No. 2000-27, Tilburg.

van Groezen, B., Leers, T., Meijdam, L., 2003. Social security and endogenous fertility: pensions and child allowances as Siamese twins. Journal of Public Economics 87, 233-251. 
Wigger, B.U., 1999. Pay-as-you-go financed public pensions in a model of endogenous growth and fertility. Journal of Population Economics 12, 625640.

Zhang, Jie, 1995. Social security and endogenous growth. Journal of Public Economics 58, 185-213. 